\title{
Role of Add-on Prednisolone in the Management of Peripheral Lymph Node Tuberculosis
}

\author{
Prahlad Rai Gupta*
}

Shalby Multispeciality Hospital, Jaipur, India

\section{Article Info}

\section{Article Notes}

Received: July 19, 2018

Accepted: August 02, 2018

\section{*Correspondence:}

Dr. Prahlad Rai Gupta, Shalby Multispeciality Hospital, Jaipur, India, Email: Guptapr_dr@hotmail.com, drprgupta52@hotmail.com

(c) 2018 Gupta PR. This article is distributed under the terms of the Creative Commons Attribution 4.0 International License.
Peripheral lymph node tuberculosis (PLNTB) is the commonest form of extra-pulmonary tuberculosis (EPTB), both in HIV infected and non-infected patients ${ }^{1,2}$. Cervical region is most frequently affected site ${ }^{3-5}$. Mycobacterium tuberculosis is the most common cause. Females and economically productive young adults are more commonly affected ${ }^{6,7}$. Tubercular lymphadenitis is mainly a medical disease as surgical excision is associated with slightly worse outcome as compared to medical treatment alone, but repeated aspiration of the affected node is sometimes required to avoid scar formation. But in spite of medical treatment, many of these patients show appearance of new lymph node or new disease, increase in the size of existing lesions and/ or sinus formation while on treatment. This becomes more problematic, while managing PLNTB in cosmosensitive area i.e. cervical lymph node tuberculosis (CLNTB). Several studies have also shown better outcomes, when oral steroids are added to anti tubercular drugs (ATT), in EPTB cases i.e. pleural effusion $^{8}$, pericardial effusion ${ }^{9}$, tubercular meningitis, mediastinal lymphadenitis causing pressure on vital structure ${ }^{10}$. But studies defining the role of add on steroids in management of PLNTB are sparse $^{11-13}$.

In this regard, an open label, randomized, prospective, interventional and comparative study by our group, Bunkar et al. ${ }^{14}$ should be a welcome sign. This study is being reviewed here in detail for the benefit of readers.

This study was conducted in patients of CLNTB at the Institute of Respiratory Diseases, Sawai Man Singh Medical College, Jaipur, Rajasthan, India. Ethical clearance for the study was obtained from the institutional ethical committee (453/MC/RC/17/12/2012) and the study was registered with Clinical Trial Registry of India (Reg. no. CTRI/2014/12/005299). Informed consent was taken from all the patients.

All treatment naive CLNTB patients were included in the study but pregnant females, persons with diabetes mellitus, hypertension, acid peptic disease, acquired immunodeficiency syndrome, alcoholics and those with preformed lymph node abscess were excluded. Their demographic data including age, sex, address and occupation detailed history of constitutional and other symptoms, past treatment history/any comorbid illness was recorded. Their vital signs and body weight were also noted down. The site, size, number, consistency, mobility and tenderness of the LN was 
noted down. Diagnosis of lymph node tuberculosis was confirmed either by cytopathological examination or microbiologically i.e. a positive acid-fast bacilli (AFB) smear of fine needle aspiration cytology (FNAC) of the lymph node. When diagnosis was not established by above methodology, excisional biopsy was also done.

The study patients were randomised into two groups i.e. Group I who were given Category I treatment (as per Revised National Tuberculosis Control Programme, India) along with prednisolone $1 \mathrm{mg} / \mathrm{kg}$ body weight for 4 weeks followed by tapering at $0.5 \mathrm{mg} / \mathrm{kg}$ body weight for 4 weeks and Group II who received Category I treatment along with placebo. Patients were kept in close follow up during treatment and after completion of the therapy for at least next 6 month and monitored for clinical, radiological and bacteriological effects and side effects of the therapy. Pearson's $x^{2}$ test or fisher's exact test and Student's t- test were used, as applicable, to establish statistical significance.

After excluding 8 patients due to poor compliance, 120 patients were available for analysis. The demographic profile showed no significant difference in both the study groups. The mean age of patients was $27.5+12.9$ for Group I \& $26.3+11.7$ for Group II. 46 were males and 74, females (M:F 1:1.60). Most patients were non-smoker and nonalcoholic. Fever, loss of weight, loss of appetite and fatigue were equally frequent in the 2 groups. Solitary lymph node was noted in 28 patients (46.7\%) in group I and 35 patients (58.30\%) in group II. Paired and multiple lymph nodes were present in $14(23.3 \%)$ and $18(30 \%)$ patients of Group I and $10(16.7 \%)$ and 15 patients (25.0\%) of Group II respectively $(\mathrm{P}>0.05)$. Majority of lymph node were mobile $\approx 96.7 \%$ and unilateral. Mantoux test was positive in $96.7 \%$ of the patients.

Skiagram chest was normal in $>90 \%$ of the patients. Pleural effusion $(2 / 120,1.67 \%)$ and miliary shadows (4/120, 3.33\%) were commonest radiological anomalies, being equally common in the 2 groups. The sputum smears were negative for acid fast bacilli in all of these patients. A total of 113 patients were diagnosed by lymph node FNAC alone. Six out of the 56 patients in group I had positive AFB smear as well as cytology, 2 had only AFB smear positivity and the remaining 48 patients had only cytopathological confirmation. The respective figures for group II were 8, 4 and 45 out of 57 patients of group II. 7 patients ( 4 in group I \& 3 in group II) were diagnosed by histopathological evidence of tuberculosis in the excised LNs.

Complete resolution seen in 57 patients (96\%) in group I and 40 patients $(66.7 \%)$ of group II respectively. The remaining 3 patients $(5 \%)$ in group I had residual lymph node (no change) while the remaining 20 patients $(33.33 \%)$ patients of group II had residual lymph nodes no change/increase in size $(\mathrm{p}<0.01)$.
Paired \& multiple lymph nodes showed 92.86\% and $94.44 \%$ resolution in group I patients respectively compared to $40.00 \%$ and $53.33 \%$ resolution in group II patients respectively $(\mathrm{p}<0.05)$. Thus, complete resolution was seen in significantly greater number of group I patients as compared to Group II. This difference was more so in patients with paired and multiple nodes. The time of resolution was also faster in group I patients as after two month, 16 patients $(26.67 \%)$ and 44 patients $(73.33 \%)$ showed complete or partial resolution of the LN as compared to only 4 patients $(6.67 \%)$ and 49 patients $(81.67 \%)$ in Group II. The Remaining 7 patients $(11.66 \%)$ of group II have no change/increase in size/number of lymph nodes $(\mathrm{p}<0.01)$.

Complications were noted in form of abscess, sinus and/or appearance of new lymph node/s. Only 3 patients in Group I (5.0\%) had complications as compared to $13(21.7 \%)$ in Group II. $(\mathrm{p}<0.001)$. All these patients needed needle aspiration/surgical exploration during the course of treatment. Sequel in form of residual lymph node was seen in 3 and 20 patients of Group I and II ( $<<0.01)$. Fever, fatigue, loss of appetite and weight improved more frequently and faster in group I patients as compared to group II patients $(\mathrm{p}<0.01)$. Gastro-intestinal side effects i.e. nausea/vomiting and pain abdomen, were slightly more common and skin rashes and joint pain were lees common in Group-I patients than Group II, but the difference was statistically insignificant ( $p>0.05)$.

The authors have concluded that add on steroids led to faster and earlier resolution of symptoms as well as the lymph nodes and was associated with less frequent complication and sequel, at least in treatment naïve patients. Add on steroid led to more frequent but selflimiting gastro-intestinal upsets.

Limitations of the study by Bunkar et al. ${ }^{14}$ : Non-inclusion of the drug sensitivity testing is a major limitation of the above study. The same is now in order in all cases of EPTB ${ }^{15}$. Other limitations include

1. lack of mention of the details of the hypothesis for the study,

\section{Lack of mention of the method of randomization and}

\section{Response as per size of the LN in result section.}

None the less this study by our group ${ }^{14}$ should open a case for use of add on steroids in the routine management of PLNTB, more specifically in treatment naïve cases of CLNTB. it is medically sound and saves ugly scars in this cosmo-sensitive area.

\section{References}

1. Shafer RW, Edlin BR. Tuberculosis in patients infected with human immunodeficiency virus: perspective on the last decade. Clin Infect Dis. 1996; 22: 683 . 
2. Hart CA, Beeching NJ, Duerden BI. Tuberculosis into the next century J Med Microbiol. 1996; 44: 1-34.

3. Lazarus AA, Thilagar B. Tuberculous Lymphadenitis. Dis Month 2007; 53: 10-15.

4. Thompson MM, Underwood MJ, Sayers RD, et al. Peripheral tuberculous lymphadenopathy: a review of 67 cases. Br J Surg. 1992; 79: 763-64.

5. Dandapat MC, Mishra BM, Dash SP, et al. Peripheral lymph node tuberculosis: a review of 80 cases. Br J Surg. 1990; 77: 911-12.

6. Chen Y, Lee P, Su W, et al. Lymph node tuberculosis: 7-year experience in Veterans General Hospital, Taipei, Taiwan. Tubercle. 1992; 73: 368.

7. Campbell IA. The treatment of superficial tuberculous lymphadenitis. Tubercle. 1990; 71: 1

8. Mansour AA, Rbeay Al. Adjunt therepy with corticosteroids or paracentesis for treatment of tuberculous pleural effusion. East mediferr health J. 2006; 12: 504-8.

9. Reuter H, Burqess LJ, Louw VJ, et al. The management of tuberculous pericardial effusion: Experience in 233 consecutive patients. Cardiovascular JS Afr. 2007; 18: 20-5.
10. Nemir RL, Cardona J, Vagiri F, et al. Prednisolone as an adjunct in the chemotherapy of bronchial tuberculosis in childhood: A double blind study II. further term observation. Am Rev Respir Dis. 1967; 95: 402 10.

11. Chhabra N, Dixit R, Aseri ML. Adjunctive corticosteroid therapy in tuberculosis management: a critical reappraisal. IJPSR, 2011; II: 1015.

12. Kadhiravan T, Deepanjali S. Role of corticosteroids in the treatment of tuberculosis: An evidence-based update. Ijcdas. 2010; 52: 153-58.

13. Blaikley JF, khalid S, Ormerod LP. Management of peripheral lymph node tuberculosis in routine practice: an unselected 10-year cohort. Int J Tuberc Lung Dis. 2011; 15(3): 375-78.

14. Bunkar ML, Agnihotri SP, Gupta PR, et al. Add-on prednisolone in the management of cervical lymph node tuberculosis. Ind J Tuber. 2016; 63: 96-99.

15. Dusthackeer A, Sekar G, Chidambaram S, et al. Drug resistance among extrapulmonary TB patients: Six years' experience from a supranational reference laboratory. The Indian Journal of Medical Research. 2015; 142: 568-74. 